Test Use and Assessment Practices of School Psychology Training Programs: Findings from a 2020 Survey of U.S. Faculty

Adam B. Lockwood

Kent State University

Nicholas Benson

Baylor University

Ryan L. Farmer

Oklahoma State University

Kelsey Klatka

Kent State University

Author Note

This is the pre-peer reviewed version of the following article: "Test Use and Assessment Practices of School Psychology Training Programs: Findings from a 2020 Survey of U.S. Faculty," which has been accepted for publication in Psychology in the Schools. This article may be used for non-commercial purposes in accordance with Wiley Terms and Conditions for Use of Self-Archived Versions. This manuscript is not the final version and differs from the final, published version. The authors declare that they have no conflict of interest. We wish to thank all the faculty members who completed this survey and who work tirelessly to train school psychologists. Correspondences concerning this article should be addressed to Adam Lockwood, Kent State University. Email: alockwo2@kent.edu. 


\begin{abstract}
The last comprehensive study to examine the assessment practices promoted by school psychology programs was published 25 years ago (i.e., Wilson \& Reschly, 1996). Since then, significant changes to assessment theory and practice have occurred. Data from a 2020 survey of directors of school psychology programs were collected to gain an understanding of current graduate training in test use and assessment. Results were compared to a current survey of practitioners as well as past surveys of trainers. Results indicate that the assessment instruments used most frequently by practitioners tend to be those that are strongly emphasized in training programs. There were significant changes over time, most notably a large increase in the extent to which programs emphasize rating scales. Programs continue to strongly emphasize standardized, norm-referenced tests, particularly tests of cognitive abilities and academic achievement. Programs also continue to emphasize behavioral observation methods. In contrast to our expectations, results also reveal a persistent emphasis on low-value instruments such as projective tests. The implications of these findings for training and practice are discussed.

Keywords: assessment; psychoeducational testing; training; classification
\end{abstract}




\section{Test Use and Assessment Practices of School Psychology Training Programs: Findings from a 2020 Survey of U.S. Faculty}

\section{Importance of Assessment}

School psychologists frequently engage in assessment related activities. Surveys dating back to the 1980s and 1990s (e.g., Goh et al., 1981; Hutton et al., 1992; Stinnett et al., 1994) have found that practitioners spend, on average, roughly half of their time engaged in special education eligibility assessment activities. This trend continues to this day; the most recent national survey by the National Association of School Psychologists (NASP) in 2020 indicated that $88 \%$ of their members spend "quite a bit" or "a great deal" of time on evaluation tasks (Goforth et al., 2021). Furthermore, Goforth and colleagues found that practitioners conduct an average of 54.7 assessments each school year. Additionally, as noted in NASP's (2020) Model for Comprehensive and Integrated School Psychological Services, which outlines the professional practices of our field, "School psychologists, in collaboration with other members of an interdisciplinary team, conduct assessments to determine students' need for services, including eligibility for special education, and to provide information relevant to the development of individual service plans" (p. 3).

NASP (2020) mandates the use of evidence-based practice in school psychology, particularly in the area of assessment. Lilienfeld and colleagues (2019) argue preventing harm is one of the - if not the most important-justifications for evidence-based practice. Conversely, the use of low-value practices (i.e., those with inadequate evidence, that cause harm, or are unnecessary; McKay et al., 2018) may lead to preventable but erroneous educational decisions that have long lasting implications for students. These implications include denying students the 
services and protections that are afforded to them as a person with a disability, which may result in academic failure. Inappropriate assessment practices may also result in the mislabeling of nondisabled students, leading to self-fulfilling prophecies of academic and/or behavioral failure (Higgins et al., 2002; Lockwood \& Coulter, 2017). Perhaps most concerning, these misdiagnoses can lead to unnecessary isolation, segregation and degradation, especially for minoritized students (Losen \& Welner, 2001). In sum, assessment duties serve as a major role of school psychologists and the use of evidence-based assessment practices is extremely important.

\section{Test Use and Assessment Practices in School Psychology}

A variety of different assessment practices are used by school psychologists to gather data regarding external variables that impact students' learning and behavior and data regarding internal variables that document how students function in important domains of functioning such as academic achievement, cognitive abilities, adaptive behavior, and personality. Formal and informal measures are used to collect data across informants, settings and procedures. Frequent assessment methods include observations, checklist/rating scales, interviews and standardized norm-referenced tests (NRTs). A number of studies (e.g., Benson et al., 2019; Goh et al., 1981; Hutton et al., 1992; Reschly et al., 1987; Stinnett et al., 1994; Wilson \& Reschly, 1996) have examined assessment practices including which psychoeducational instruments are used most frequently by school psychologists. Benson and colleagues provided a comprehensive review of these studies and noted that comprehensive psychoeducational evaluations in the 1980s and 1990s were largely dominated by tests of cognitive ability, academic achievement, personality and perceptual/motor functioning, though observations and interviews were frequently used as well. The most commonly used measure during these decades was the Weschler Intelligence scales followed by the Bender-Gestalt (Bender, 1946) and the Draw-A-Person (Harris, 1963) 
projective test. Other frequently used measures included the Woodcock Johnson Tests of Achievement (WJ ACH; Woodcock \& Johnson, 1989) and Kaufman Assessment Battery for Children (KABC; Kaufman \& Kaufman, 1983). With the exception of the use of projective drawing instruments (e.g., Draw-A-Person), these studies found that school psychologists generally used psychometrically sound instruments to conduct comprehensive, multi-informant, multi-method assessment. For a more detailed synthesis of these studies see Benson and colleagues.

Most recently, Benson et al. (2019) conducted an exhaustive survey of 1317 practicing school psychologists in the United States regarding their current test use and assessment practices. Benson and colleagues found that practitioners continued to frequently engage in assessment tasks with 24 separate assessment instruments used at least once a month, on average. These authors also noted that tests of cognitive ability continue to be used extensively, most notably the Wechsler Intelligence Scale for Children, $5^{\text {th }}$ Edition (WISC-V; Wechsler, 2014), which was used by $80 \%$ of participants ( $m=3.5$ per month) far more than the second most used measure the Differential Ability Scales - II (DAS-2; Elliot, 2007; 35\%; $m=2.3$ per month). Omnibus tests of academic achievement continued to be administered frequently. The most commonly used being the Kaufman Test of Educational Achievement, $3^{\text {rd }}$ Edition (KTEA-3; Kaufman \& Kaufman, 2014; 62\%; $m=1.9$ per month), the Wechsler Individual Achievement Test $3^{\text {rd }}$ Edition (WIAT-III; Wechsler, 2009; 47\%; $m=1.8$ per month), and the WJ ACH IV (Schrank, Mather, \& McGrew, 2014; 50\%; $m=1.8$ per month). Interviews and observations are also frequently employed by school psychologists. The most frequent interview technique, the developmental interview, was conducted by $69 \%$ of participants ( $m=2.9$ times per month), while the most frequent observation method, interval recording, was used by $60 \%$ of participants 
( $m=1.6$ per month). Like earlier surveys (i.e., Goh et al., 1981; Hutton et al., 1992; Reschly et al., 1987; Stinnett et al., 1994; Wilson \& Reschly, 1996), Benson and colleagues found a continued underemphasis on measures of early childhood and neuropsychological assessments. For example, the most frequently used neuropsychological measure, the Beery Visual-Motor Integration (VMI; Beery et al., 2010) was used by 33\% of participants ( $m=0.9$ times per month) while the most commonly used early childhood instrument, the Bracken Basic Concept Scale (Bracken, 2006), was used by $17 \%$ of participants ( $m=0.3$ time per month).

The biggest differences in test use over the past three decades that was noted by Benson et al. (2019) was a significant increase in the use of rating scales, especially broad-band behavioral scales such as the Behavior Assessment System for Children, Third Edition - Teacher Rating Scale (BASC-3TRS; Reynolds \& Kamphaus, 2015a), which was the most commonly used instrument by participants (91\%; $m=3.7$ times per month). Narrow-band rating scales, particularly those used in the assessment of attention deficit hyperactivity disorder (ADHD) (e.g., Behavior Rating Inventory of Executive Function, Second Edition [BRIEF2] Teacher form; Gioia et al., 2015; 50\%; $m=1.0$ times per month) have also seen a rise in use as have measures of adaptive behavior (e.g., Adaptive Behavior Assessment Scales, Third Edition [ABAS-3]; Harrison \& Oakland, 2015; 69\%; $m=1.5$ times per month). An increase was also noted in instruments used to assess symptoms of autism spectrum disorder (ASD), which were reported by $82 \%$ of participants, though no mention of assessment of autism was made in any previous surveys. Another major shift in assessment practices was a move away from projective tests. In the 1990s these measures were widely used; Benson and colleagues found that less than a third of participants used projective tests at all, and those that did employ these tests, generally used them less than once a month. Tests of perceptual/motor functioning have also seen significant 
declines. For example, the Bender-Gestalt, which was consistently the third or fourth most widely used instrument in the 1980 s and 1990 s, is now used by $11 \%$ of participants $(m=.3$ times per month) and is the $57^{\text {th }}$ most administered (Benson et al., 2019).

The other major change noted by Benson and colleagues (2019) was the increased use of assessment-related technology; while virtually non-existent during the 1980s and 1990s, technology was used by $97 \%$ of participants to aid in the scoring of various instruments by 2017 at least occasionally. Participants used computer-based software (e.g., software of publishermaintained websites) to score behavioral rating scales roughly $78 \%$, tests of cognitive ability $65 \%$, adaptive behavior scales $60 \%$, tests of academic achievement approximately $58 \%$, and selfreports approximately $48 \%$ of the time. Technology-assisted administration appeared less frequent than scoring, with only behavioral rating scales and tests of cognitive ability administered more than a quarter of the time by participants, on average. Also, likely due to the proliferation of technology, at least one Curriculum Based Measure (CBM) is now administered by $85 \%$ of participants, greater than $50 \%$ of which was carried out using computer measures from vendors such as AIMSweb, DIBELS and easyCBM (Benson et al., 2019).

\section{Assessment Training Practices}

Despite the centrality of assessment to our profession and extensive research related to test use and assessment practice for practitioners, limited information regarding the scope and content of school psychology assessment curricula exists (Benson et al., 2019; Lockwood \& Farmer, 2020; Miller et al., 2020). The last study to examine the topic across assessment measures (e.g., cognitive, achievement, personality) was published 25 years ago (i.e., Wilson \& Reschly, 1996) and relied on data that is now nearly 30 years old. This study of 156 faculty members compared their results to a survey of 166 college faculty published roughly a decade 
earlier (i.e., Reschly et al., 1987), both of which examined the supervised practice experiences that are provided in programs. Findings suggested that the most common measures of cognitive ability were the Weschler scales (96\% in 1996; 95\% in 1986) followed by the Stanford-Binet scales (92\% in 1986; $79 \%$ in 1996), and the Kaufman scales (52\% in $1986 ; 55 \%$ in 1996). The most common academic achievement measures were the Woodcock-Johnson scales $(67 \%$ in 1986; 59\% in 1996), the Peabody Individual Achievement Test (PIAT; Markwardt, 1989) (67\% in 1986; $51 \%$ in 1996), the KTEA (39\% in 1996; no data for 1986), and Curriculum Based Assessment (CBA)/CBM (22\% in 1996; no data for 1986). The Bender Gestalt was the most commonly used perceptual motor scale and was administered by over $70 \%$ of programs. Trainers reported using projective techniques frequently; of these, the Draw-A-Person approach was administered by trainees in close to $70 \%$ of programs. Rating scales were not heavily used with only the Vineland Adaptive Behavior Scales (Sparrow et al., 1984) used by more than half of programs. Observations were commonly required with more than half of programs requiring the recording of duration, interval, time, event, and anecdotal data. More detailed information regarding instrument training across the decades can be found in Table 1 examining changes in training across studies.

$<$ Insert Table 1 here>

While no other studies have examined assessment training overall, multiple studies have examined the tests used during the initial course on cognitive assessment. The first such study was a survey conducted by Oakland and Zimmer (1986) of 49 school psychology graduate instructors, which was replicated by Alfonso and colleagues (2000) with a sample of 97 instructors. More recently, Lockwood and Farmer (2020) surveyed 98 school psychology faculty members and Miller et al. (2020) conducted an analysis of 90 syllabi. Like Reschly and 
colleagues (1987) and Wilson and Reschly (1996), all of these studies found that the Weschler child scales were administered by almost all trainees and that the Kaufman child scales were administered by a modest number of trainees during this initial course. The biggest change in test use over the years was the decrease in the administration of the Stanford-Binet scales, which appears to have been supplanted by the Woodcock-Johnson Tests of Cognitive Ability (WJ COG; Schrank, McGrew, \& Mather, 2014). This shift was consistent across studies (with the exception of the Wilson and Reschly article, which did not collect data regarding the WJ COG). Another change in test use practices that was noted by Lockwood and Farmer was a decrease in the use of adult and preschool measures compared to previous research.

Other cognitive assessment training trends were noted. For example, both Lockwood and Farmer (2020) and Miller et al. (2020) described an increase in the use of technology-based test administration and scoring (which did not exist at the time that the other studies were conducted), though this uptick was modest with less than $14 \%$ requiring an electronic administration in either study. Lockwood and Farmer also found that $61 \%$ of test administrations are scored using a technical manual (versus computer or web-based software). Additionally, both studies suggested that issues related to culturally/linguistically diverse assessment are addressed more frequently now than in the past. However, Miller and colleagues found that close to a quarter of programs do not address these topics while Lockwood and Farmer found that only $51 \%$ of instructors indicated that assessment of culturally and/or linguistically diverse populations was of "great" emphasis in the course.

\section{Purpose}

Since Wilson and Reschly’s (1996) study, significant changes in education have occurred, most notably the passage of the Individuals with Disabilities Education Act (IDEA, 
[2004]), which eliminated the requirement of detecting a "severe discrepancy" between cognitive ability and academic achievement. Significant changes in theory, including the development of Cattell-Horn-Carroll (CHC) theory (Schneider \& McGrew, 2012), have also occurred.

Additionally, demographic shifts in the U.S. student population have occurred as has a rise in the prevalence of ASD. Perhaps due to these changes, Benson and colleagues (2019) found significant shifts in test use and assessment practices overall, while Lockwood and Farmer (2020) and Miller et al. (2020) found transformations in what is taught during the first course on cognitive assessment. Some of these changes, such as a significant reduction in the use of projective measures (Benson et al., 2019) and other low-value practices (e.g., cognitive subtest interpretation and comparison), reflect a move away from low-value practices toward evidencebased practices. Indeed, the evidence-based assessment (EBA) movement has gained traction in school psychology in the past few years (see McGill, 2019). While the presence of the EBA framework and growing empirical support for (and against) various practices is most likely a contributor to this trend, the shift is not uniform; there remains a science-to-practice gap in the field (Allen \& Hanchon, 2013). Given the influence of graduate training (Cook et al, 2009; Sotelo-Dynega \& Dixon, 2014) on professional practices, the continued instruction of low-value practices described by Lockwood \& Farmer (2020) and Miller et al. (2020) is a concern and suggests a science-to-pedagogy gap as well.

Due to the changes noted above, the centrality of assessment to school psychology, the high-stakes nature of assessment, and the importance of graduate training to practice behavior, an updated picture of training in assessment appears overdue. Lockwood and Farmer (2020) and Miller et al. (2020) solely gathered information about assessment practices and test use during one class (i.e., the initial course on cognitive assessment). The last comprehensive survey of 
assessment training (i.e., Wilson \& Reschly, 1996) reported data that were collected during 1991-1992. A current, thorough understanding of curricula is needed to understand the totality of training provided across assessment courses, fieldwork, practicum, and internship. The purpose of this study is to address this need. Specifically, we will provide an overview of current test use and assessment practices in school psychology training programs and compare our findings to practitioners' test use and assessment practices as reported by Benson and colleagues. Additionally, we will discuss similarities in reported training between our study and Lockwood and Farmer (2020) and Miller et al. (2020) as well as similarities and changes in training that have occurred since the last comprehensive survey on test use and assessment practices published by Wilson and Reschly (1996).

\section{Method}

This research was approved by the lead author's institutional review board. Participation was voluntary and informed consent was provided electronically. Survey methods are reported using Eysenbach's (2004) Checklist for Reporting Results of Internet ESurveys.

\section{Participants}

Participants included 105 trainers of school psychologists in universities across the United States. Approximately $81 \%$ of participants indicated that their program was NASP approved, 38\% indicated that their program was accredited by the American Psychological Association (APA), and $16 \%$ indicated that their program was not recognized by NASP or APA. Most participants were White (83\%) women (67\%). Participants reported an average age of 47 $(S D=9)$ years, $12(S D=8)$ of which they had spent working at their current university. A specialist degree was the most common degree offered by participants' programs and was reported by $80 \%$, followed by doctorate $(43.5 \%)$ and master's $(26 \%)$. To protect the anonymity 
of the limited number of trainers, state data regarding where the institution was located was not collected. To determine the extent to which the sample generalized to the U.S. school psychology training program population, two chi-square statistics were calculated. Results suggested that the sample did not differ significantly from the population in terms of doctoral vs. non-doctoral degree programs, $\chi^{2}(\mathrm{df}=1)=0.92, \mathrm{p}=.34$, or NASP approval for programs, $\chi^{2}(\mathrm{df}$ $=1)=0.04, \mathrm{p}=.85$.

\section{Participant Recruitment}

Two recruitment methods were used to maximize the likelihood that program directors would receive an invitation to participate. First, a recruitment email letter with a survey link was emailed to the directors of the 237 school psychology graduate programs listed on the NASP website (https://apps.nasponline.org/standards-and-certification/graduate-education/index.aspx) in late September 2020. A follow-up email was sent in October of 2020. All participants had the option of participating in a drawing for one of two $\$ 50$ gift cards. Second, we obtained approval from the Trainers of School Psychology (TSP) to post recruitment emails on their listserv. In total, we made two TSP listserv posts in November 2020 requesting participation that resulted in an additional 43 responses. Seventy-nine and 43 responses were initiated via direct e-mail and listserv recruitment strategies, respectively. Of the 122 responses initiated, 105 were found to be valid cases. Data exclusion details are provided in the Analysis section below.

\section{Survey Design}

The survey instrument was designed to gather demographic information and information about the test use and assessment training experiences provided to school psychology trainees. Initial items were selected from Benson et al.'s (2019) questionnaire, then adapted to reflect the emphasis on training instead of practice. The survey was piloted and reviewed by three content 
experts (i.e., three faculty trainers of school psychologists from three separate institutions, each with experience teaching assessment and multiple publications in the area of psychoeducational assessment) and two school psychology graduate students with experience administering assessment measures. Items were revised, added, and deleted based on the feedback of these reviewers following Dillman et al.'s (2014) recommendation to minimize measurement and nonresponse error.

\section{Survey Administration}

The survey was administered using the Qualtrics cloud software platform. Participants had the ability to access the survey via their preferred electronic device (e.g., tablet, computer, or smartphone). The survey consisted of 38 items, 14 of which were matrix tables and 24 were sliders. An option of "other" was provided for all multiple choice and matrix table items. Median completion time for the survey was 1340 seconds (22.3 minutes). A PDF version of the electronic survey is available via Open Science Framework at https://OSF.IO/(blinded for review). Of note, continuous rating items were used for emphasis on a range from 0-10 (with $0=$ No emphasis and $10=$ Great emphasis $)$. The reason for this is that continuous rating scales improve a measure's reliability, allow for more precise input from participants, generate interval data, increase the probability of normally distributed responses and decrease the probability of a ceiling effect (Chyung et al., 2018).

\section{Analysis}

The dataset was downloaded from Qualtrics on 12/2/2020. The downloaded data consisted of 124 records; of these two were previews used when piloting the study that were deleted. Six records (three pairs) from duplicated IP addresses were found; each of these pairs consisted of one record with responses from the original email request and one from the listserv 
request that did not have any responses suggesting that the participant opened the survey, realized that they had already participated, and quit. For each of these duplicates, the least complete record was deleted (three total). Records were also analyzed by longitude and latitude and no duplicates were found. Two participants clicked "disagree" on the informed consent button and were deleted. Additionally, 12 records were found that agreed to participate but did not complete a single item and were excluded, resulting in 105 participants. Sixteen participants (15.2\%) dropped out after completing the first page, which contained two items (one pertaining to program emphasis on assessment and one regarding the percentage of minoritized students assessed). Another three participants (2.9\%) completed eight items (first two pages), while 15 (14.3\%) completed 12 items (first three pages), one (1.0\%) completed 13 items and one (1.0\%) completed 17 items. A total of $69(65.7 \%)$ completed the full survey. Missing data were examined and found to be monotone (Little \& Rubin, 2002; Schafer \& Graham, 2002) meaning that items that were left incomplete were done so largely due to drop out. Missing data of this source is referred to as completely random dropout (Diggle \& Kenward, 1994) and considered to be a special case of missing completely at random (MCAR; Little, 1995; Rubin, 1976). However, we wanted to detect if any systematic differences were present between participants that completed the survey versus those that did not. Specifically, we hoped to determine if nonrespondents did not finish because their program does not emphasize assessment. To determine if this was the case, a series of Mann-Whitney U tests were used to examine differences in program emphasis in assessment; nonsignificant differences in assessment emphasis between completers and non-completers were found for each variable $(p s=.524-.916)$. Full results of the Mann-Whitney U tests, as well as a redacted copy of the survey data are available at https://osf.io/ (blinded for review). 


\section{Results}

\section{General Description of Assessment Training}

Participants indicated that trainees dedicate an average of $55.4 \%(S D=15 \%)$ of their applied experience (e.g., fieldwork, practicum, internship) to assessment practices; $53.2 \%$ of this time was dedicated to report writing. The average percent of assessment services provided to special education students was $56 \%(S D=23 \%)$ compared to $29 \%(S D=19 \%)$ dedicated to general education assessment.

Program directors were asked to rate the extent to which programs emphasize various topics from 0 (no emphasis) to 10 (great emphasis). Results indicated that programs emphasize experiences that prepare future school psychologists to assess elementary $(m=9.54)$, middle $(m$ $=8.72)$, and high school students $(m=8.46)$. Programs tend to place minimal emphasis on training that addresses services to other age groups, particularly infants $(m=1.90)$. Roughly $37 \%$ $(S D=21 \%)$ of the k-12 students that trainees assess are considered Black, Indigenous, and People of Color (BIPOC). With respect to disability categories, programs place the greatest amount of emphasis on Specific Learning Disability (SLD; $m=7.94$ ), and significantly less on gifted assessment $(m=2.46)$. Only moderate attention is paid to issues related to the assessment of Culturally and Linguistically Diverse (CLD) students. Average ratings of emphasis range from 6.72 (assessment of CLD student in general) to 2.76 (administration of the Batería III Woodcock-Muñoz, [Schrank et al., 2005]). Additionally, programs appear to be placing a greater emphasis on the use of Response to Intervention (RtI) to identify SLD (7.49) while eschewing use of an intelligence-achievement discrepancy (3.98). More regarding program emphases can be seen in Table 2.

$<$ Insert Table 2 here> 


\section{Use of Assessment Instruments}

Participants were asked to "mark all tests that students administer as part of their training (i.e., coursework, fieldwork, practicum, internship)." Therefore, percentages represent the percent of participants that marked each specific test. Percentages for reported use of each procedure and test are presented in Table 3. A priori items as well as all write-in (“other") responses that were reported by three or more participants are provided. Tests are ranked by overall use and by type. Additionally, Benson et al.'s (2019) rankings are provided to allow for comparison.

<Insert Table 3 here>

\section{Tests of Cognitive Abilities}

Tests of cognitive abilities continue to be frequently used in training programs. About $97 \%$ of participants indicated that they require administration of tests of cognitive abilities. The average number of distinctive (e.g., WISC-V vs. KABC-II vs. WJ IV COG) measures administered throughout a trainee's education is $5.5(S D=2.44)$. The most commonly administered measures are the WISC-V, WJ IV COG, and KABC-II administered in 92.8\%, $81.2 \%, 65.2 \%$ of programs, respectively. Adult measures are rarely administered, with the exception of the Wechsler Adult Intelligence Scale, $4^{\text {th }}$ Edition (WAIS-IV; Wechsler, 2008), which is administered by students in $44.9 \%$ of programs. Non-verbal tests are administered by $53.6 \%$ of programs' trainees with the most used being the Universal Nonverbal Intelligence Test - 2 (UNIT-2; Bracken \& McCallum, 2016), which is administered in $37.7 \%$ of programs. Brief measures tend to be rarely administered with the most common, the Kaufman Brief Intelligence Test, $2^{\text {nd }}$ Edition (KBIT-2; Kaufman \& Kaufman, 2004), administered by trainees in just $11.6 \%$ of programs. 


\section{Tests of Academic Achievement}

Roughly $94.2 \%$ of participants reported that they require students to administer omnibus tests of academic achievement. The average number of distinct measures administered by each program was $2.4(S D=0.71)$. The most frequently reported omnibus measures consist of the WJ IV $\mathrm{ACH}$, which is administered by $87.3 \%$ of programs, followed by the WIAT-3 $(76.1 \%)$ and the KTEA-3 (64.8\%). Narrow band academic achievement tests are used by $60.9 \%$ of programs. The most commonly administered of these are the Gray Oral Reading Test, $5^{\text {th }}$ Edition (GORT-5; Wiederholt \& Bryant, 2012; 35.2\%) and KeyMath-3 (Connolly, 2007; 29.6\%).

Academic progress monitoring measures are administered by trainees in $91.9 \%$ of programs. Roughly $88 \%$ of participants indicated that their trainees gain experience administering measures of oral reading fluency, followed by reading comprehension (84.9\%), math computation (76.7\%), early literature (69.8\%), math concepts and applications $(69.8 \%)$, written expression (67.4\%), early numeracy (58.1\%), and spelling (55.8\%). The specific CBM vendors that trainees most often administer included: DIBELS (59.3\%), EasyCBM (43.0\%), and AIMSweb (41.9\%). Approximately 5\% indicated that students administer other instruments (e.g., self-created CBMs). No programs required students to administer Edcheckup.

Participants indicated that other measures of academic achievement are used beyond progress monitoring and omnibus measures. Specifically, the Comprehensive Test of Phonological Processing, $2^{\text {nd }}$ Edition (CTOPP-2; Wagner et al., 2013) is administered by 49.3\% of programs followed by brief experimental analyses of academic skills (e.g., Can’t Do/Won't Do Assessment; Daly et al., 1997; 43.7\%), and portfolio and performance or authentic assessment (19.7\%).

Tests for Assessing Symptoms of ASD 
ASD measures are administered by trainees in $53.6 \%$ of programs. The Childhood Autism Rating Scale, Second Edition (Schopler, et al., 2010) is the most frequently administered measure, reported by $40.6 \%$ of programs, followed by the Gilliam Autism Rating Scale, Third Edition (GARS-3; Gilliam, 2013; 27.5\%), Autism Diagnostic Observation Schedule, Second Edition (ADOS-2; Lord et al., 2012; 15.9\%), and Gilliam Asperger's Disorder Scale (GADS; Gilliam, 2001; 11.6\%).

\section{Behavior Rating Scales}

All participants reported that trainees administer at least one behavior rating scale measure during their graduate training to a guardian and/or teacher. The BASC-3 Parent Rating Scales (PRS) are the most commonly administered (97.1\% of trainees), followed by the BASC-3 TRS (94.2\%). Another omnibus behavioral rating scale is frequently administered; the Conners Comprehensive Behavior Rating Scales Parent and Teacher scales (Conners, 2008a) are used in $50.7 \%$ and $47.8 \%$ of programs, respectively. More specifically, participants indicated that when training graduate students to administer the most used measure (i.e., BASC-3), 88.3\% reported they always or almost always require the Parent form, $79.6 \%$ always or almost always require a general education teacher form, $55.1 \%$ from a special education teacher, and $52.2 \%$ always or almost always require a self-report.

The Conners 3 Parent and Teacher Scales (Conners, 2008b) were the most commonly reported narrow band behavior scale measures, administered by trainees in $63.8 \%$ and $62.3 \%$ of programs, respectively; the BRIEF2 Teacher and Parent Forms are also frequently administered (58.0\% and $56.5 \%$ of programs). The next most frequently administered narrow band is the Children's Depression Inventory (CDI-2; Kovacs, 2010), which is administered by trainees in $42.0 \%$ of programs. 
Approximately $84 \%$ of participants reported that trainees engage in some form of social emotional progress monitoring. The most commonly used screener is the Behavioral and Emotional Screening System (BASC-3 BESS; Kamphaus \& Reynolds, 2015), which is administered by $66.3 \%$ of programs' trainees. This measure is used significantly more frequently than the next most commonly used, the Student Risk Screening Scale (SRSS; Drummond, 1994), which was reported by $18.6 \%$ of participants.

\section{Behavioral Observations}

Approximately $94 \%$ of programs require trainees to engage in behavioral observations. Antecedent-behavior-consequent $(\mathrm{ABC})$ recording forms are the most frequently used observational method, conducted by $82.6 \%$ of programs. Interval $(72.5 \%)$, event $(65.2 \%)$, and duration (63.8\%) methods are also utilized. Published observation methods are slightly less commonly used and the most popular, the BASC-3 Student Observation System, is administered by trainees in $46.4 \%$ of programs.

\section{Adaptive Behavior}

Roughly $96 \%$ of programs' trainees administer some measure of adaptive behavior during their training experience. The most widely administered measures are the ABAS-3 (Harrison \& Oakland, 2015), and the Vineland Adaptive Behavior Scales, Third Edition (Vineland-3; Sparrow et al., 2016) both of which are used by $71.8 \%$ of program trainees. Other adaptive rating scales systems appear to be rarely administered.

\section{Self-report Forms}

The most commonly administrated self-report measure is the BASC-3 SRP, which is used by $87.0 \%$ of programs. The next most frequently administered omnibus self-report, the Achenbach System of Empirically Based Assessment (ASEBA) Youth Self-Report (Achenbach 
$\&$ Rescorla, 2001), is used by just $24.6 \%$ of programs. The most commonly used narrow-band self-report is the BRIEF2 Self-Report Form (50.7\%), followed by the CDI-2 (42.0\%), Beck Depression Inventory (Beck et al., 2005; 37.7\%), and Beck Anxiety Inventory (BAI; 31.9\%).

\section{Projective Tests}

Roughly $38 \%$ of programs require participants to administer at least one projective measure during training. The most commonly administered projective tests are sentence completion tests, which are used by $29.0 \%$ of programs. Projective drawings are also administered, including the Draw-A-Person (23.2\%), House-Tree-Person (HTP; Buck, 1964; 21.7\%), and the Kinetic Family Drawing (Burns \& Kaufman, 1970; 20.3\%;) tests. More traditional and time intensive projective tests such as apperception tests (e.g., Thematic Apperception Test [TAT]; Morgan \& Murray, 1935) and the Rorschach are administered less frequently.

\section{Tests of Early Development}

Tests of early development are administered in only $47.8 \%$ of programs. The most frequently used measures are the Bayley Scales of Infant and Toddler Development (Bayley-III; Bayley, 2006) and Battelle Developmental Inventory ${ }^{\mathrm{TM}}$, Second Edition (BDI-2; Newborg, 2005 ), both of which are administered in roughly $19 \%$ and $16 \%$ of programs, respectively.

\section{Neuropsychological Tests}

Approximately $61 \%$ of programs require trainees to administer neuropsychological tests. The most common of which are the Bender Visual-Motor Gestalt Test, Second Edition (Brannigan \& Decker, 2003) and the NEPSY-II (Korkman et al., 2007), both of which are administered in $27.5 \%$ of programs. Traditional neuropsychological tests designed to determine 
brain injuries are rarely used; the most commonly of which, the Wisconsin Card Sorting Test (Heaton et al., 1993) is administered in only $7.2 \%$ of programs.

\section{Assessment Technology Use}

The vast majority of participants indicated that trainees use software or online services to administer $(91.3 \%)$ or score $(95.7 \%)$ at least one assessment measure. On average, participants report that $58.8 \%$ of parent and teacher rating scales are scored by trainees using computer methods. Approximately $56 \%$ of cognitive measures are scored this way as are $53.7 \%$ of achievement tests. Parent/teacher and self-report rating scales are the most frequently electronically administered measure, done so $28.0 \%$ and $27 \%$ of the time, respectively. More details regarding electronic scoring can be found in Table 4.

$<$ Insert Table 4 here>

\section{Interviews}

Approximately $94 \%$ of participants reported that trainees are required to conduct some form of structured interview. Parental developmental history interviews (84.1\%) and functional assessment interviews with teachers $(63.8 \%)$ are the most frequently used interview types. Participants also reported that trainees frequently use Problem-solving interview (a.k.a. problem identification and problem analysis interview; 62.3\%), and functional assessment interviews with parents (63.7\%). Unstructured interviews with children/adolescents (23.2\%) are not frequently used nor are diagnostic interviews (18.8\%) with children.

\section{Discussion}

Several recent publications (e.g., Lockwood \& Farmer, 2020; Miller et al., 2020) have examined the initial course on cognitive assessment. However, school psychologists frequently administer many other types of assessments (e.g., behavioral checklists, CBMs; Benson et al., 
2019) and gain much more assessment experience than is provided in the initial course on cognitive assessment. The last comprehensive study of assessment training in school psychology was published over 25 years ago (i.e., Wilson \& Reschly, 1996). This is despite a significant shift in the theories, legal mandates, and practices related to assessment in our field. This current study fills the gap in the literature by examining the current test use and assessment training practices of school psychology trainees in the United States across coursework, fieldwork, practicum, and internship.

\section{Similarities}

The biggest constant in school psychology assessment training appears to be an emphasis on cognitive assessment. Of the top 10 most frequently administered measures during training, two are measures of cognitive ability (i.e., WISC-V and WJ IV COG). The most common measure, the WISC-V, is administered in nearly $93 \%$ of programs. This finding comports with studies of school psychology training going back some 35 years ago and is consistent with more recent research (e.g., Lockwood \& Farmer, 2020; Miller et al., 2020) on the initial course on cognitive assessment, and with Benson et al.'s (2019) survey of practitioners; all of these studies suggest that the dominance of the Weschler Intelligence Scales continues. However, like Benson et. al., and Lockwood and Farmer, we found that the Stanford-Binet is no longer heavily used, while use of the Woodcock-Johnson has increased significantly. Additionally, like Benson et al. we found that only BASC-3 rating scales are more commonly used than the WISC-V. Interestingly, though there has been a number of non-verbal (e.g., The UNIT-2) and shorter measures (e.g., Reynolds Intellectual Assessment Scales, Second Edition [Reynolds \& Kamphaus, 2015b]) published since Wilson and Reschly (1996), they are not widely administered by trainees - findings that are consistent with Benson and colleagues. 
Like Benson et al. (2019), we found that neuropsychological measures were not endorsed by most participants suggesting that these measures are not frequently administered during training or by most in the field. The most commonly reported measure on both surveys was the Beery VMI (ranked number 26 and 41 respectively). Our finding that roughly $41 \%$ of programs have students administer the Beery VMI is in line with Wilson and Reschly's (1997) study, which found that $45 \%$ of programs did in the mid-to-late 1990s (Reschly et al.'s 1987 study did not include the measure).

There also appears to be a continued lack of emphasis on measures of early childhood development. The most commonly used measure, the Bayley scale, was endorsed by approximately $19 \%$ of participants, slightly down from the two previous training surveys, both of which found that this measure was administered by $24 \%$ of program trainees. Our ranking of the Bayley at 79 is also fairly consistent with Benson et al.'s (2019) ranking of 104 suggesting that most practitioners do not frequently administer this measure either.

Like Wilson and Reschly (1996) and Reschly et al. (1987), observations and interviews continue to be frequently administered during training. This same trend was found in Benson et al.'s (2019) study suggesting that practitioners continue to conduct observations and interviews frequently. However, while findings from both Benson et al. and our survey suggest that developmental history interviews are the most commonly used interview method by trainees and practitioners, the second most endorsed interview technique, the unstructured interview, was far less commonly endorsed in our survey (ranked 7 and 67, respectively).

\section{Changes}

While similarities exist, much has changed in the test use and assessment practices promoted by training programs compared to Wilson and Reschly (1996) and Reschly et al.'s 
(1987) surveys. Most notably, there has been significant increase in the use of rating scales by school psychology programs. Because Wilson and Reschly's data were collected in 1991-1992, data regarding the use of the BASC, which was first published in 1992 (RAND, 2013), was not available. During the 1980s and 1990s the most commonly used rating scales were the Vineland and ASEBA Child Behavior Checklist (CBCL) and only the Vineland was administered by more than $50 \%$ of program trainees during either survey. Showing prescience, Wilson and Reschly noted that rating scales were underused and stated that "(A)nother area ripe for development is the use of rating scales for problem behaviors, adaptive behavior, and social skills" (p. 18). These authors were correct as the BASC-3-PRS and -TRS were the number one and number two most used measures in our survey, and the number one and number three in Benson et al.'s (2019). Additionally, four narrow-band measures were endorsed by greater than $50 \%$ of respondents including the Conners-3 parent and teacher forms, and the BRIEF2 parent and teacher form. Similar patterns were noted by Benson et al. and are unsurprising considering that ADHD accounts for $18 \%$ of referrals (Benson et al., 2019).

Relatedly, social emotional progress monitoring and measures of ASD have become common place. No mention of either type of assessment were noted in previous training studies suggesting that they were not commonly administered by trainees during the 1980s and 1990s. Interestingly, our survey found significantly higher use of screeners (84\% vs. 20\%) and less use of ASD measures (54\% vs. $82 \%)$ than did Benson and colleagues.

Another significant shift was a decrease in the use of projective instruments. In both Wilson and Reschly (1996) and Reschly et al.'s (1987) surveys, administration of four projective measures (i.e., Draw-A-Person, HTP, Kinetic Family drawing, and TAT) were required by trainees from $50 \%$ or more of programs; the most commonly used of these measures, Draw-A- 
Person, was administered by $68 \%$ and $75 \%$ of programs' trainees, respectively. We found that approximately $38 \%$ of programs require the administration of a projective test during training and no specific projective measure was administered by a quarter or more of programs, with the exception of $29 \%$ of programs requiring sentence completion tasks. This indicates that use of projective measures is on the decline and that programs that do require them now emphasize writing over drawing tasks. Similar trends in the use of projective tests were noted by Benson et al. (2019).

There has also been a significant increase in the administration of measures of academic achievement. Most notable, CBM use has increased from 22\% in Wilson and Reschly's (1996) publication to roughly $92 \%$ in current training programs (CBM use was not measured in Reschly et al.'s 1987 study) with CBM of reading fluency, reading comprehension and math computation all making the top 10 on our list. Additionally, we found an increase in the use of omnibus measures including the WJ IV ACH which was administered by approximately $87 \%$ of programs' trainees compared to 59\% and 67\% in Wilson and Reschly and Reschly et al.'s surveys, respectively. The second most administered omnibus measure, the WIAT-3 is required by $76 \%$ of programs though the first edition of this measure was not published until after Wilson and Reschly's data collection (Martelle \& Smith, 1994). Similar, trends were also noted in Benson et al.'s survey indicating that both practitioners and trainees administer more tests of academic achievement assessment than in the past.

The other major trend that was noted was an increase in the use of computer/technology. Computer aided scoring and administration technology was not widely available during the 1980s and 1990. In fact, only Reschly et al. (1986) measured technology use which was largely concerned with whether participants had access to a computer (62\%) and a modem (14\%) at 
work. Our findings suggest that approximately $91 \%$ of programs require trainees to electronically administer, and roughly $98 \%$ to electronically score, at least one measure. These findings are consistent with Benson et al. (2019) suggesting that access to computers and internet has increased extensively and that there has been an explosion in the use of technology for assessment purposes both by training programs and practitioners.

\section{Implications for Training}

There are a number of implications for training that can be posited based on our findings. First, tests of cognitive abilities continue to be frequently used in training programs. This emphasis is consistent with professional demands, as reviews of state criteria indicate that assessment of intellectual functioning is widely required when identifying intellectual disability (McNicholas et al., 2018) and giftedness (McClain \& Pfeiffer, 2012). Although there is little evidence to support interpretation of cognitive strengths and weaknesses as a supplement to or replacement for a general factor of intelligence (e.g., Beaujean \& Benson, 2019), many programs continue to emphasize the assessment of multiple, specific cognitive abilities. This is problematic because such assessments are time intensive and lack evidence to support their diagnostic utility (McGill et al., 2018) and instructional relevance (Burns et al., 2015). While we readily acknowledge that legal and/or district regulations often require school psychologists to administer comprehensive, multidimensional measures of intelligence, psychometrically sound brief measures are available but not frequently used. We encourage training programs to have students use these measures whenever possible and appropriate. When brief measures are not appropriate due to cultural and/or linguistic issues, we encourage trainers to prepare bilingual examiners who can administer tests in an examinee's native language (when possible) in addition 
to English-language tests. When appropriate tests or qualified bilingual examiners are unavailable, trainers should encourage the use of nonverbal tests.

Second, and relatedly, issues related to the assessment of diverse learners appears to be under emphasized. This included little reported emphasis on the administration of the Batería III Woodcock-Muñoz and moderate emphasis on issues related to assessment of CLD students. Additionally, only $37 \%$ of the k-12 students that trainees assess are considered BIPOC, while $48 \%$ of the k-12 student population in Fall 2017 were White (which is projected to decrease to 44\% by Fall 2029; Institute of Education Sciences, 2020). These findings are fairly commensurate with Lockwood and Farmer (2020), who found that only roughly $50 \%$ of cognitive assessment courses place a great emphasis on this topic, and Miller et al. (2020) who noted that nearly a quarter of instructors do not address issues related to assessment of CLD students in their syllabi. We encourage programs to make assessment of diverse learners a greater emphasis so that their trainees can better serve the majority of students that they will work with during their career.

Third, there is an apparent shift away from using projective measures, which are plagued with issues related to reliability and validity (Lilienfeld et al., 2000; Lilienfeld et al., 2012), to behavioral rating scales. While this finding is promising, close to $40 \%$ of programs still require students to administer projective measures during their training and change is still needed. It is possible that programs require students to use projective tests as an "ice breaker" or to help build rapport rather than for diagnostic purposes. While such practices may cause no harm, we believe that this time would be better spent talking to students, asking them questions, or otherwise engaging with them on preferred tasks (see Lugo et al, 2017). Additionally, we believe that having trainees administer these measures provides tacit approval for, and thus perpetuates, their 
use. In short, we can think of no appropriate reason that any trainee should use time or any other scarce resources in this manner and hope that trainers will consider eliminating the use of projective tests in their programs.

Fourth, programs have decreased the amount of emphasis placed on using an intelligence-achievement discrepancy in isolation to determine SLD. This is important due to concerns related to reliability and validity (Francis et al., 2005; Maki \& Adams, 2020) and instructional relevance (Vaughn \& Fuchs, 2003). Unfortunately, decreased emphasis on intelligence-achievement discrepancy has been accompanied by increased emphasis on alternatives (i.e., RtI, patterns of strengths and weaknesses [PSW] approaches) that also lack evidence of validity supporting their use for SLD identification decisions. PSW approaches have been criticized for lacking treatment utility (e.g., McGill \& Busse, 2017; McGill et al., 2018) and there is scant federal law regarding the use of PSW. Thus, school districts increase their potential liability when they opt to use a PSW approach (Corbin, 2021). Likewise, there are concerns with the use of RtI for SLD identification decisions in that they may not show an accurate depiction of a student's response to an intervention and/or not discriminate between SLD and other disability categories (Lindstrom \& Sayeski, 2013).

We encourage programs to have candid discussions with trainees about the shortcomings and potential advantages of approaches used to identify SLD. Although RtI has limitations as a means of identifying SLD, unlike intelligence-achievement discrepancy and PSW approaches, it emphasizes evidence-based instruction and continuous progress monitoring. While no strategy or program works for all students all the time, the use of evidence-based instruction increases the probability of successful outcomes. Another positive finding in this survey is increased coverage of progress monitoring (both academic and social emotional). Numerous progress monitoring 
tools have been developed and practitioners can evaluate the evidence supporting their use at the National Center on Intensive Intervention's website.

In general, our findings mirror those of Benson and colleagues (2019) suggesting that changes in training reflect those of practice or vice versa. The continued inclusion of low-value practices, such as projective testing and profile-based interpretation of cognitive measures, is likely maintained by a number of variables, including how trainers and practitioners were trained with regard to such instruments (Cook et al., 2009), the perpetuation of such practices in training materials (Farmer et al., 2020), and district guidelines that continue to mandate such practices (e.g., Lockwood et al. 2021a; Cottrell \& Barrett, 2016). Practitioners often use techniques that they are taught in graduate school (Cook et al., 2009; Sotelo-Dynega \& Dixon, 2014). Therefore, it is also likely that school psychologists are using what they believe to be evidence-based practice due to the training they received. To combat this, not only should programs have direct conversations regarding the problems with the assessment practices they are teaching, but they must also be up to date on the literature and good consumers of research so that they avoid teaching low-value assessment practices.

We recognize that many districts may require the use of low-value practices and that it would be problematic for a graduate program to inadequately prepare students for local practicum or professional positions. For example, like Benson et al. (2019), we found that brief cognitive measures are rarely used; therefore, it may be that training programs do not emphasize their use because they will not be administered by trainees in their future districts. However, when programs are required to teach low-value practices, we strongly encourage programs to have candid conversations with trainees regarding the problems with the assessment practices that they are teaching and the possible negative outcomes of these practices. Having these frank 
discussions and teaching students how to identify low-value practices will help trainees better recognize them and be better prepared to make decisions about their use (Lawson \& Brown, 2018; Zaboski \& Therriault, 2019). Furthermore, we hope that programs will encourage trainees to act as change agents in their districts and beyond to advocate for a shift away from low-value assessment practices (see Shaw, 2021 for a discussion of de-implementation of low-value practices).

One notable difference between professional preparation and practice is that practitioners use universal screening procedures less often than expected given that these procedures are now emphasized in many training programs. Universal screening procedures are used to identify students who need early intervention services. Access to intervention can improve educational and mental health outcomes. As previously mentioned, only $20 \%$ of practitioners report that they engage in screening despite the fact that $84 \%$ of training programs prepare students to use screening procedures. This discrepancy likely relates to barriers that exist within school settings. Such barriers include limited awareness of the technical adequacy and utility of screening approaches among school stakeholders, budgetary limitations, concerns about student privacy, and concerns about diverting time and effort from other efforts used to meet school accountability requirements (Albers et al., 2007). Additional training may be needed to ensure that future school psychologists are prepared to advocate for and play leadership roles in universal screening and early intervention initiatives.

Another notable difference between professional preparation and practice is that practitioners use instruments to assess symptoms of ASD more frequently than expected given that only $54 \%$ of programs require students to administer these instruments. There is a strong need for practitioners who can identify students with ASD using evidence-based instruments 
(Wilkinson, 2010). Thus, it is not surprising that $82 \%$ of practitioners report using these instruments (Benson et al., 2019). Given this need we encourage trainers who do not do so already, to require students to practice administering and scoring these instruments.

\section{Limitations and Areas for Future Research}

This study, like all survey research, relied on self-reports of behavior. Participants may not have provided accurate data due to unfamiliarity with the practices of their trainees, recall error, or because they wanted to be viewed in a favorable light (i.e., due to social desirability bias). However, as the survey was sent out to program directors, the likelihood that the participants did not understand their program requirements is low, though they may have an incomplete understanding. Additionally, due to the anonymous nature of this survey, threats due to social desirability bias would appear to be low. However, future researchers may wish to examine permanent records such as course syllabi, program handbooks, practica/internship logs, and other documents to gain a more objective and comprehensive understanding of training practices.

Relatedly, there were several items that had excessive missing data. All of these items used Qualtrics’ slider question format, which was used to make items more engaging for participants. Additionally, these items measured the percent of software and online services used. Upon examining these items, it appears likely that low-frequency practices (e.g., scoring and administering neuropsychological tests and interviews) were unanswered because the participants believed that a response of $0 \%$ was the default, and warranted no change on their part. For this reason, some of these software and online service items are likely overestimates and should be interpreted with caution. This is especially true of items with greater than $20 \%$ missing data. If we infer that all of the missing data for items with greater than $50 \%$ non- 
responses were intended to be zeros then percentages would decrease by between roughly two thirds (neuropsychological test administration would change from $14.3 \%$ to $4.4 \%$ ), to slightly more than half (developmental test administration would drop from $12.0 \%$ to $5.6 \%$ ). Making the same assumption for items with $20-50 \%$ missing data, values would decrease by a magnitude of anywhere from roughly half (behavioral observation administration would change from $20.9 \%$ to $10.6 \%$ ) to approximately a quarter (adaptive behavior administration would drop from $19.8 \%$ to $14.2 \%)$. For more information regarding the extent of missing data, please see the notes of Table 4.

Another possible limitation of this study was our sample size. As previously noted, only 69 (29.1\% of the total population) participants completed the entire survey. This is likely due to the comprehensive nature of our study ( 22-minute completion time). To control for possible non-response error, we ran a series of Mann-Whitney U Tests and did not find any systematic differences on key outcome variables between completers and non-completers. Furthermore, dropout is generally considered an instance of MCAR, which is considered a strong assumption that does not introduce bias (Osborne, 2013). Additionally, researchers (e.g., Massey \& Tourangeau, 2013; Perneger et al., 2005; Pike, 2012) have suggested that little difference exists between responders and nonresponders and that response rates likely have a minimal influence on survey research conclusions. Furthermore, non-response rates of $60 \%$ or greater are not uncommon even for major national surveys (Massey \& Tourangeau, 2013). However, future researchers may wish to use a briefer survey to reduce completion time to obtain a larger sample size.

In this paper, we attempted to compare our findings to Wilson and Reschly (1996) and to Reschly et al. (1987) to determine changes in assessment training practices over time. We also 
compare our findings to those of Benson et al. (2019). However, exact comparison was not possible because the two previous training surveys asked participants to provide data regarding what tests were administered during 'supervised practice.' As this term was not operationally defined in either publication and may have left out some assessment administrations (e.g., tests administered as part of an assessment class) we asked participants to indicate whether tests were "administered by trainees in... the entirety of their training program (i.e., coursework, fieldwork, practicum, internship)." Additionally, Benson and colleagues provided data on the percent of practitioners that reported using each specific measure as well as their average test use per month. We did not collect data on average test use per month due to the limited number of assessments that most school psychology trainees conduct each month. For this reason, our comparisons may not be completely one to one.

Relatedly, because test use data were gathered dichotomously (i.e., either used or not used), it is possible that we underestimated or overestimated the use of some measures. For example, while the WISC-V was administered in almost all programs, it is possible that many of these programs require very few administrations. Conversely, while few programs required the Batería III, these programs could have required trainees to administer this test often. Future research may wish to gather data regarding the number of administrations required per measure to provide a more nuanced picture of test use.

Finally, because we wanted to protect the anonymity of our small number of training programs, we did not collect data on state or regional differences. However, recent research suggests that assessment roles vary greatly across demographic regions, especially the West where special education teachers are the most frequent administrators of NRTs of academic achievement used to determine special education eligibility (Lockwood et al., 2021a). 
Additionally, in some states (e.g., Louisiana) school psychologists do not generally administer tests of academic achievement, instead relying on educational diagnosticians (Lockwood et al., 2021b, Louisiana Department of Education, 2009), while others (e.g., Iowa) rely on CBMs to determine SLD eligibility (Maki et al., 2015). Future researchers may wish to examine regional and state differences in training to see if these differences in legal mandates and assessment roles affect test use and assessment training practices across programs.

\section{Conclusion}

Assessment is a major role of school psychologists and failure to use evidence-based assessment practices can have long-term, negative effects. Therefore, examining the training that graduate students receive is paramount. Some changes in test use and assessment training have occurred over the past 30 years; most notably there has been an increase in the administration of rating scales, CBMs and the use of assessment-related technology and a decrease in the use of projective tests. The biggest consistency is that IQ measures continue to dominate assessment training. Additionally, the findings of this study and other research (e.g., Lockwood \& Farmer, 2020; Maki \& Adam, 2019; Miller et al., 2020) suggests a mismatch between evidence-based practice and our pedagogical choices as school psychology trainers; a veritable science-topedagogy gap. School psychology trainers should identify evidence-based assessment practices across a variety of contexts and the low-value practices across those same contexts. Furthermore, trainers should prepare trainees to engage in evidence-based assessment and to identify lowvalue practices while still preparing them to be marketable in a field that often requires practitioners to engage in assessment practices that may be suspect. 


\section{References}

Achenbach, T. M., \& Rescorla, L. A. (2001). Manual for the ASEBA school-age forms and profiles: An integrated system of multi-informant assessment. University of Vermont Research Center for Children, Youth, \& Families.

Albers, C. A., Glover, T. A., \& Kratochwill, T. R. (2007). Where are we, and where do we go now? Universal screening for enhanced educational and mental health outcomes. Journal of School Psychology, 45(2), 257-263. https://doi.org/10.1016/j.jsp.2006.12.003

Alfonso, V. C., LaRocca, R., Oakland, T. D., \& Spanakos, A. (2000). The course on individual cognitive assessment. School Psychology Review, 29, 52-64. https://doi.org/10.1080/02796015.2000.12085997

Allen, R.A. \& Hanchon, T.A. (2013). What can we learn from school-based emotional disturbance assessment practices? Implications for practice and preparation in school psychology. Psychology in the Schools, 50. 290-299. https://doi.org/10.1002/pits.21671

Bayley, N. (2006). Bayley scales of infant and toddler development (3rd ed.). Pearson.

Beaujean, A. A., \& Benson, N. F. (2019). The one and the many: Enduring legacies of Spearman and Thurstone on intelligence test score interpretation. Applied Measurement in Education, 32, 198-215. https://doi.org/10.1080/08957347.2019.1619560

Beck, J. S., Beck, A. T., Jolly, J. B., \& Steer, R. A. (2005). Beck youth inventories for children and adolescents (2nd ed.). Pearson.

Beery, K. E., Buktenica, N. A., \& Beery, N. A. (2010). The Beery-Buktenica developmental test of visual-motor integration (6th ed.). Pearson.

Bender, L. (1946). Instructions for the use of visual motor gestalt test. The American Orthopsychiatric Association, Inc. 
Benson, N. F., Floyd, R. G., Kranzler, J. H., Eckert, T. L., Fefer, S. A., \& Morgan, G. B. (2019). Test use and assessment practices of school psychologists in the United States: Findings from the 2017 national survey. Journal of School Psychology, 72, 29-48. https://doi.org/10.1016/j.jsp.2018.12.004

Bracken, B. A. (2006). Bracken basic concept scale-receptive (3rd ed.). Pearson.

Bracken, B. A., \& McCallum, R. S. (2016). Universal nonverbal intelligence test (2nd ed.). PRO-ED.

Brannigan, G. G., \& Decker, S. L. (2003). Bender visual-motor gestalt test (2nd ed.). Riverside. Buck, J. N. (1964). The house-tree-person. Western Psychological Services.

Burns, M. K., Petersen-Brown, S., Haegele, K., Rodriguez, M., Schmitt, B., Cooper, M., Clayton, K., Hutcheson, S., Conner, C., Hosp, J., \& VanDerHeyden, A. M. (2015). Metaanalysis of academic interventions derived from neuropsychological data. School Psychology Quarterly, 31(1), 28-42. https://doi.org/10.1037/spq0000117

Burns, R. C., \& Kaufman, S. H. (1970). Kinetic family drawings (K-F-D): An introduction to understanding children through kinetic drawings. Brunner/Mazel.

Chyung, S. Y., Swanson, I., Roberts, K., \& Hankinson, A. (2018). Evidence-based survey design: The ese of continuous rating scales in surveys. Performance Improvement, 57(5), 38-48. https://doi.org/10.1002/pfi.21763

Conners, C. K. (2008a). Conners comprehensive behavior rating scales. WPS Publish.

Conners, C. K. (2008b). Conners rating scales (3rd ed.). Pearson.

Connolly, A. J. (2007). Keymath-3 diagnostic assessment. Upper Saddle Creek. 
Cook, J. M., Schnurr, P. P., Biyanova, T., \& Coyne, J. C. (2009). Apples don't fall far from the tree: Influences on psychotherapists' adoption and sustained use of new therapies. Psychiatric Services, 60(5), 671-676.

Corbin, C. (2021, January). Legally defensible assessments, child find, COVID-19 pandemic issues: Concerns \& questions [Conference session]. North Eastern Affiliate of the California Association of School Psychologists (NECASP) Workshop, Virtual.

Cottrell, J. M., \& Barrett, C. A. (2016). Defining the undefinable: Operationalization of methods to identify specific learning disabilities among practicing school psychologists. Psychology in the Schools, 53(2), 143-157. https://doi.org/10.1002/pits.21892

Daly, E. J., III, Witt, J. C., Martens, B. K., \& Dool, E. J. (1997). A model for conducting a functional analysis of academic performance problems. School Psychology Review, 26, $554-574$.

Diggle, P., \& Kenward, M. G. (1994). Informative drop-out in longitudinal data analysis. Applied Statistics, 43, 49-93. https://doi.org/10.2307/2986113

Dillman, D. A., Smyth, J. D., \& Christian, L. M. (2014). Internet, phone, mail, and mixed-mode surveys: The tailored design method (4th ed.). John Wiley \& Sons, Inc.

Drummond, T. (1994). The student risk screening scale. Josephine County Mental Health Program.

Elliot, C. D. (2007). Differential ability scales (2nd ed.). Harcourt Assessment.

Eysenbach, G. (2004). Improving the quality of web surveys: The checklist for reporting results of internet esurveys (CHERRIES). Journal of Medical Internet Research, 29(6(3)), e34. https://doi.org/10.2196/jmir.6.6.e34 
Farmer, R. L., McGill, R. J., Dombrowski, S. C., \& Canivez, G. L. (2020). Why questionable assessment practices remain popular in school psychology: Instructional materials as pedagogic vehicles. Canadian Journal of School Psychology.

\section{https://doi.org/10.1177/0829573520978111}

Francis, D. J., Fletcher, J. M., Stuebing, K. K., Lyon, G. R., Shaywitz, B. A., \& Shaywitz, S. E. (2005). Psychometric approaches to the identification of LD: IQ and achievement scores are not sufficient. Journal of Learning Disabilities, 38, 98-108. https://doi.org/10.1177/00222194050380020101

Gilliam, J. E. (2001). Gilliam Asperger's disorder scale. WPS Publish.

Gilliam, J. E. (2013). Gilliam autism rating scale (3rd ed.). PRO-ED.

Gioia, G. A., Isquith, P. K., Guy, S. C., \& Kenworthy, L. (2015). The behavior rating inventory of executive function (2nd ed.). Psychological Assessment Resources.

Goforth, A. N., Farmer, R. L., Kim, S. Y., Affrunti, N., Naser, S. C., \& Lockwood, A. (2021, February). School psychology: A national perspective from the NASP 5-year membership survey [Conference session]. National Association of School Psychologists (NASP), 53rd Annual Convention, Salt Lake City, UT, United States.

Goh, D. S., Teslow, C. J., \& Fuller, G. B. (1981). The practice of psychological assessment among school psychologists. Professional Psychology, 12, 696-706. https://doi.org/10.1037/0735-7028.12.6.696

Harris, D. B. (1963). Children's drawings as measures of intellectual maturity. Harcourt, Brace \& World.

Harrison, P. L., \& Oakland, T. (2015). Adaptive behavior assessment system (3rd ed.). Pearson. 
Heaton, R. K., Chelune, G. J., Talley, J. L., Kay, G. G., \& Curtiss, G. (1993). Wisconsin card sorting test. Psychological Assessment Resources.

Higgins, E., Raskind, M., Goldberg, R., \& Herman, K. (2002). Stages of acceptance of a learning disability: The impact of labeling. Learning Disability Quarterly, 25(1), 3-18. https://doi.org/10.2307\%2F1511187

Hutton, J. B., Dubes, R., \& Muir, S. (1992). Assessment practices of school psychologists: Ten years later. School Psychology Review, 21, 271-284.

Individuals with Disabilities Education Act, Publ. L. No. 108-446. (2004). https://www .copyright.gov/legislation/pl108-446.pdf

Institute of Education Sciences. (2020, May). Racial/ethnic enrollment in public schools. https://nces.ed.gov/programs/coe/indicator cge.asp

Kamphaus, R. W., \& Reynolds, C. R. (2015). Behavior assessment system for children - third edition (BASC-3). Pearson Assessment.

Kaufman, A. S., \& Kaufman, N. L. (1983). Kaufman assessment battery for children. American Guidance Service.

Kaufman, A. S., \& Kaufman, N. L. (2004). Kaufman brief intelligence test (2nd ed.). Pearson.

Kaufman, A. S., \& Kaufman, N. L. (2014). Kaufman test of educational achievement (3rd ed.). Pearson.

Korkman, M., Kirk, U., \& Kemp, S. (2007). NEPSY-II: A developmental neuropsychological assessment (2nd ed.). Psychological Corporation.

Kovacs, M. (2010). The children's depression inventory (2nd ed.). Multi-Health Systems. 
Lawrence, G. W., \& Saklofske, D. H. (2020). Mediators of IQ test score differences across racial and ethnic groups: The case for environmental and social justice. Personality and Individual Differences, 161(15). https://doi.org/10.1016/j.paid.2020.109962

Lawson, T. J., \& Brown, M. (2018). Using pseudoscience to improve introductory psychology students' information literacy. Teaching of Psychology, 45(3), 220-225. https://doi.org/10.1177/0098628318779259

Lilienfeld, S. O., Ammirati, R. J., \& David, M. (2012). Distinguishing science from pseudoscience in school psychology: Science and scientific thinking as safeguards against human error. Journal of School Psychology, 50(1), 7-36. https://doi.org/10.1016/j.jsp.2011.09.006

Lilienfeld, S. O., Ritschel, L. A., Lynn, S. J., \& Latzman, R. D. (2019). The insufficiently appreciated raison d'être of evidence-based practice. In S. Dimidjian (Ed.), Evidencebased practice in action: Bridging clinical science and intervention. Guilford Press.

Lilienfeld, S. O., Wood, J. M., \& Garb, H. N. (2000). The scientific status of projective techniques. Psychological Science in the Public Interest, 1(2), 27-66. https://doi.org/10.1111\%2F1529-1006.002

Lindstrom, J. \& Sayeski, K. (2013). Identifying Best practice in a shifting landscape: Making sense of rti in the context of SLD identification, Exceptionality, 21(1), 5-18, https://doi.org/10.1080/09362835.2013.750111

Little, R. J. (1995). Modeling the drop-out mechanism in repeated-measures studies. Journal of the American Statistical Association, 90, 1112-1121. https://doi.org/10.2307/2291350

Little, R. J., \& Rubin, D. B. (2002). Statistical analysis with missing data. Wiley. 
Lockwood, A., \& Coulter, A. (2017). Rights without labels: Thirty years later. Communique, 45(6).

Lockwood, A., \& Farmer, R. L. (2020). The cognitive assessment course: Two decades later. Psychology in the Schools, 57, 265-283. https://doi.org/10.1002/pits.22298

Lockwood, A., Farmer, R. L., Bohan, K., Winans, S., \& Sealander, K. (2021a). Academic achievement test use and assessment practices: A national survey of special education administrators. Journal of Psychoeducational Assessment. https://doi.org/10.1177\%2F0734282920984290

Lockwood, A., Farmer, R. L., Winans, S., \& Sealander, K. (2021b). Specific learning disability identification practices in the U.S.: A survey of special education administrators. Contemporary School Psychology. https://doi.org/10.1007/s40688-021-00375-4

Lord, C., Rutter, M., DiLavore, P. C., Risi, S., Gotham, K., \& Bishop, S. L. (2012). Autism diagnostic observation schedule (2nd ed.). Western Psychological Services.

Losen, D. J., \& Welner, K. G. (2001). Disabling discrimination in our public schools: Comprehensive legal challenges to inappropriate and inadequate special education services for minority children. Harvard Civil Rights-Civil Liberties Law Review, 36, 407460.

Louisiana Department of Education. (2009). Bulletin 1508: Pupil appraisal handbook.

Lugo, A. M., King, M. L., Lamphere, J. C., \& McArdle, P. E. (2017). Developing procedures to improve therapist-child rapport in early intervention. Behavior Analysis in Practice, 10(4), 395-401. 
Maki, K. E., \& Adams, S. R. (2019). A current landscape of specific learning disability identification: Training, practices, and implications. Psychology in the Schools, 56(1), 1831. https://doi.org/10.1002/pits.22179

Maki, K. E., \& Adams, S. R. (2020). Specific learning disabilities identification: Do the identification methods and data matter?. Learning Disability Quarterly, 43(2), 63-74. https://doi.org/10.1177/0731948719826296

Maki, K. E., Floyd, R. G., \& Roberson, T. (2015). State learning disability eligibility criteria: A comprehensive review. School Psychology Quarterly, 30(4), 457-469. https://doi.org/10.1037/spq0000109

Mardell, C., \& Goldenberg, D. S. (2011). Developmental indicators for the assessment of learning (4th ed.). Pearson.

Markwardt, F. C. (1989). Peabody individual achievement test (Revised). American Guidance Service.

Martelle, Y., \& Smith, D. K. (1994, March). Relationship of the WIAT and WJ-R tests of achievement in a sample of students referred for learning disabilities [Conference session]. 1994 Annual Meeting of the National Association of School Psychologists (NASP), Seattle, WA, United States.

Massey, D. S., \& Tourangeau, R. (2013). Where do we go from here? Nonresponse and social measurement. The ANNALS of the American Academy of Political and Social Science, 645(1), 222-236. https://doi.org/10.1177/0002716212464191

Mather, N., \& Wendling, B. J. (2015). Essentials of WJ IV tests of achievement. John Wiley \& Sons. 
McClain, M.-C., \& Pfeiffer, S. (2012). Identification of gifted students in the United States today: A look at state definitions, policies, and practices. Journal of Applied School Psychology, 28(1), 59-88. https://doi.org/10.1080/15377903.2012.643757

McGill, R. J. (Ed.). (2019). Evidence-Based Assessment in School Psychology [Special issue]. Contemporary School Psychology, 23(1).

McGill, R. J., \& Busse, R. T. (2017). When theory trumps science: A critique of the PSW model for SLD identification. Contemporary School Psychology, 21(1), 10-18. https://doi.org/10.1007/s40688-016-0094-x

McGill, R. J., Dombrowski, S. C., \& Canivez, G. L. (2018). Cognitive profile analysis in school psychology: History, issues, and continued concerns. Journal of School Psychology, 71, 108-121. https://doi.org/10.1016/j.jsp.2018.10.007

McKay, V. R., Morshed, A. B., Brownson, R. C., Proctor, E. K., \& Prusaczyk, B. (2018). Letting go: Conceptualizing intervention de-implementation in public health and social service settings. American Journal of Community Psychology, 62(1-2), 189-202. https://doi.org/10.1002/ajcp.12258

McNicholas, P. J., Floyd, R. G., Woods, I. L., Jr., Singh, L. J., Manguno, M. S., \& Maki, K. E. (2018). State special education criteria for identifying intellectual disability: A review following revised diagnostic criteria and Rosa's Law. School Psychology Quarterly, 33(1), 75-82. (Supplemental)

Miller, L. T., Bumpus, E. C., \& Graves, S. L. (2020). The state of cognitive assessment training in school psychology: An analysis of syllabi. Contemporary School Psychology, 1-8. 
Morgan, C. D., \& Murray, H. A. (1935). A method for investigating phantasies. The thematic apperception test. Archives of Neurology and Psychiatry, 34, 289-306. https://doi.org/10.1001/archneurpsyc.1935.02250200049005

National Association of School Psychologists (NASP). (2020). Model for comprehensive and integrated school psychological services. https://www.nasponline.org/x55315.xml

National Center on Intensive Interventions (n.d.). Progress monitoring. https://intensiveintervention.org/data-based-individualization/progress-monitoring.

Newborg, J. (2005). Battelle developmental inventory (2nd ed.). Riverside.

Pike, G. R. (2012). NSSE benchmarks and institutional outcomes: A note on the importance of considering the intended uses of a measure in validity studies. Research in Higher Education, 54(2), 149-170. https://doi.org/10.1007/s11162-012-9279-y

RAND. (2013, October 3). Behavior assessment system for children (BASC). https://www.rand.org/education-and-labor/projects/assessments/tool/1992/ behaviorassessment-system-for-children-basc.html

Reschly, D. J., Genshaft, J., \& Binder, M. S. (1987). The 1986 NASP survey: Comparison of practitioners, NASP leadership, and university faculty on key issues. Washington, DC: National Association of School Psychologists.

Reynolds, C. R., \& Kamphaus, R. W. (2015a). Behavioral assessment system for children (3rd ed.). Pearson.

Reynolds, C. R., \& Kamphaus, R. W. (2015b). Reynolds intellectual assessment scales (2nd ed.). Psychological Assessment Resources.

Rubin, D. B. (1976). Inference and missing data. Biometrika, 63, 581-592. https://doi.org/10.2307/2335739 
Schafer, J. L., \& Graham, J. W. (2002). Missing data: Our view of the state of the art. Psychological Methods, 7, 147-177. https://doi.org/10.1037/1082-989x.7.2.147

Schneider, W. J., \& McGrew, K. S. (2012). The Cattell-Horn-Carroll model of intelligence. In D. P. Flanagan \& P. L. Harrison (Eds.), Contemporary intellectual assessment: Theories, tests, and issues (3rd ed.; pp. 91-144). New York, Guilford Press.

Schopler, E., Van Bourgondien, M. E., Wellman, G. J., \& Love, S. R. (2010). The childhood autism rating scale (2nd ed.). Multi-Health Systems.

Schrank, F. A., Mather, N., \& McGrew, K. S. (2014). Woodcock-Johnson IV tests of achievement (WJ-IV-ACH). Riverside.

Schrank, F. A., McGrew, K. S., \& Mather, N. (2014). Woodcock-Johnson IV tests of cognitive abilities. Riverside.

Schrank, F. A., McGrew, K. S., Ruef, M. L., Alvarado, C. G., Muñoz-Sandoval, A. F., \& Woodcock, R. W. (2005). Batería III Woodcock-Muñoz. Riverside Publishing.

Shaw, S. R. (2021). Implementing evidence-based practices in school psychology: Excavation by de-implementing the disproved. Canadian Journal of School Psychology. https://doi.org/10.1177/08295735211000513

Sotelo-Dynega, M., \& Dixon, S. G. (2014). Cognitive assessment practices: A survey of school psychologists. Psychology in the Schools, 51, 1031-1045. https://doi.org/10.1002/pits.21802

Sparrow, S. S., Balla, D. A., \& Cicchetti, D. V. (1984). Vineland adaptive behavior scales. American Guidance Service.

Sparrow, S. S., Cicchetti, D. V., \& Saulnier, C. A. (2016). Vineland adaptive behavior scales (3rd ed.). Pearson. 
Stinnett, T. A., Harvey, J. M., \& Oehler-Stinnett, J. (1994). Current test usage by practicing school psychologists: A national survey. Journal of Psychoeducational Assessment, 12, $331-350$.

Vaughn, S., \& Fuchs, L. S. (2003). Redefining learning disabilities as inadequate response to instruction: The promise and potential problems. Learning Disabilities Research \& Practice, 18, 137-146. https://doi.org/10.1111/1540-5826.00070

Wagner, R., Torgesen, J., Rashotte, C., \& Pearson, N. A. (2013). Comprehensive test of phonological processing (2nd ed.). Pearson.

Wechsler, D. (2008). Wechsler adult intelligence scale (4th ed.). Pearson.

Wechsler, D. (2009). Wechsler individual achievement test (3rd ed.). Pearson.

Wechsler, D. (2014). Wechsler intelligence scale for children (5th ed.). Pearson.

Wiederholt, J. L., \& Bryant, B. (2012). Gray oral reading test (5th ed.). PRO-ED.

Wilkinson, L. A. (2010). A best practice guide to assessment and intervention for autism and Asperger's syndrome in schools. Jessica Kingsley.

Williams, J., \& Miciak, J. (2018). Adoption costs associated with processing strengths and weaknesses methods for learning disabilities identification. School Psychology Forum, Research in Practice, 12(1), 17-29.

Wilson, M. S., \& Reschly, D. J. (1996). Assessment in school psychology training and practice. School Psychology Review, 25, 9-23.

Woodcock, R. W., \& Johnson, M. B. (1989). Woodcock-Johnson psycho-educational batteryrevised. Riverside. 
Zaboski, B. A., \& Therriault, D. J. (2020). Faking science: Scientificness, credibility, and belief in pseudoscience. Educational Psychology, 40(7), 820-837. https://doi.org/10.1080/01443410.2019.1694646 
Table 1

Compares Percent Administered or Supervised Practice to Prior Surveys

\begin{tabular}{|c|c|c|c|}
\hline & $\begin{array}{l}\text { Current } \\
\text { Study }\end{array}$ & $\begin{array}{c}\text { Wilson \& } \\
\text { Reschly, } 1996\end{array}$ & $\begin{array}{c}\text { Reschly et al. } \\
1987\end{array}$ \\
\hline Instrument & $\begin{array}{c}\text { Percent } \\
\text { administered }\end{array}$ & $\begin{array}{c}\text { Percent } \\
\text { supervised } \\
\text { practice }\end{array}$ & $\begin{array}{c}\text { Percent } \\
\text { supervised } \\
\text { practice }\end{array}$ \\
\hline Wechsler Scales ${ }^{\mathrm{a}}$ & 93 & 96 & 97 \\
\hline $\mathrm{CBA} / \mathrm{CBM}$ & 92 & 22 & - \\
\hline $\begin{array}{l}\text { Woodcock-Johnson Tests of } \\
\text { Achievement }\end{array}$ & 87 & 59 & 67 \\
\hline Interval observations & 73 & 58 & 75 \\
\hline Event observations & 65 & 56 & 75 \\
\hline $\begin{array}{l}\text { Kaufman Assessment Battery } \\
\text { for Children }\end{array}$ & 65 & 55 & 52 \\
\hline $\begin{array}{l}\text { Kaufman Test of Educational } \\
\text { Achievement }\end{array}$ & 65 & 39 & - \\
\hline Duration observations & 64 & 54 & 75 \\
\hline Vineland-Classroom ${ }^{\mathrm{b}}$ & 64 & 46 & 61 \\
\hline Conners $^{c}$ & $47^{1}-51^{2}$ & 27 & - \\
\hline Vineland-Interview & 58 & 54 & 61 \\
\hline $\begin{array}{l}\text { Wechsler Preschool and } \\
\text { Primary Scale of Intelligence }\end{array}$ & 46 & 82 & - \\
\hline $\begin{array}{l}\text { Beery-Buktenica } \\
\text { Development Test of Visual- } \\
\text { Motor Integration }\end{array}$ & 41 & 45 & - \\
\hline Child Behavior Checklist & 32 & 41 & 21 \\
\hline $\begin{array}{l}\text { Bender Visual-Motor Gestalt } \\
\text { Test }\end{array}$ & 28 & 70 & 87 \\
\hline $\begin{array}{l}\text { Stanford-Binet Intelligence } \\
\text { Scales }\end{array}$ & 25 & 79 & 92 \\
\hline Draw-A-Person & 23 & 68 & 75 \\
\hline House-Tree Person & 22 & 53 & 60 \\
\hline Kinetic Family Drawing & 20 & 50 & 57 \\
\hline Bayley Scales & 19 & 24 & 24 \\
\hline Thematic Apperception Test & 13 & 54 & 64 \\
\hline
\end{tabular}

Notes. Percentages in the current study were rounded to the nearest ones place to be consistent with the reporting of the previous studies. 
${ }^{\mathrm{a}}$ Weschler Scales were comprised of any Weschler Scale in use at the time of each study. ${ }^{\mathrm{b}} \mathrm{The}$ current study reported data from the Teacher Form, (Vineland-3) because it is the modern equivalent of the Classroom Edition (Bailey-Richardson, 1988). ${ }^{\mathrm{c} C o n n e r s ~ v e r s i o n ~ n o t ~ l i s t e d ~ i n ~}$ Reschly et al. (1987). The current study used the ${ }^{1}$ Comprehensive Teacher and ${ }^{2}$ Parent forms of the Conners 3 because the original version was comprehensive (Evans \& Preston, 2011) and these studies did not differentiate between forms. 


\section{Table 2}

Emphasis Placed on Topics Featured in Academic Assessment Training

\begin{tabular}{|c|c|}
\hline \multirow{2}{*}{\multicolumn{2}{|c|}{$\begin{array}{l}\text { Topic/Subtopic } \\
\text { Developmental Level }\end{array}$}} \\
\hline & \\
\hline Elementary & $9.45(1.07)$ \\
\hline Middle & $8.72(1.71)$ \\
\hline High & $8.46(1.83)$ \\
\hline Preschool & $3.93(2.02)$ \\
\hline Post-secondary & $3.46(2.82)$ \\
\hline Infant & $1.90(2.13)$ \\
\hline \multicolumn{2}{|l|}{ Referral } \\
\hline Specific Learning Disability (SLD) & 7.94(2.04) \\
\hline Emotional Disturbance & $6.56(2.55)$ \\
\hline Behavior/Conduct Disorder & $6.44(2.56)$ \\
\hline Intellectual Disability & $6.25(2.77)$ \\
\hline Autism Spectrum Disorder & $5.95(2.69)$ \\
\hline Attention Deficit/Hyperactivity Disorder (ADHD) & $5.80(2.71)$ \\
\hline Developmental Delay & $4.26(2.73)$ \\
\hline Language Disorder & $3.16(2.27)$ \\
\hline Traumatic Brain Injury & $2.64(2.19)$ \\
\hline Low-incidence (e.g., blindness, deafness or physical impairment) & 2.49(1.97) \\
\hline Gifted or Talented & $2.46(1.88)$ \\
\hline \multicolumn{2}{|l|}{ Current Issues Related to English Learners } \\
\hline Assessment of Culturally and Linguistically Diverse Student & $6.67(2.56)$ \\
\hline Assessment of English Language Proficiency & $5.27(3.12)$ \\
\hline Assessment of Native Language Proficiency & $4.99(3.17)$ \\
\hline Administration of nonverbal or language reduced Intelligence Tests & $4.70(2.60)$ \\
\hline Administration of Parent Scales Translated into Parent's Native & \\
\hline Language & $3.55(2.99)$ \\
\hline Administration of Self-report Scales Translated into Student's Native & \\
\hline Language & $3.08(3.12)$ \\
\hline Administration of the Batería III Woodcock-Muñoz & $2.76(2.67)$ \\
\hline \multicolumn{2}{|l|}{ Frameworks for Identifying SLD } \\
\hline Response to Intervention (RtI) & $7.49(2.39)$ \\
\hline Combination of RtI and PSW & $5.66(3.01)$ \\
\hline Patterns of Strengths and Weaknesses (PSW) & $5.15(2.90)$ \\
\hline Combination of RtI and Discrepancy Model & $4.84(3.33)$ \\
\hline Discrepancy Model & $3.98(2.87)$ \\
\hline
\end{tabular}

Notes. Great emphasis $=10$ and no emphasis $=0$. Lower means indicate less overall emphasis. 


\section{Table 3}

Average Percent Administered in Training Programs and Comparison to Benson et al.'s (2019) Ranking

\begin{tabular}{|c|c|c|c|c|}
\hline \multicolumn{2}{|r|}{ Assessment instrument and overall rank by percent administered by trainee } & \multirow{2}{*}{$\begin{array}{c}\% \text { administered } \\
97.1\end{array}$} & \multirow{2}{*}{$\begin{array}{c}\text { Type \& rank } \\
\text { RS } 1\end{array}$} & \multirow{2}{*}{$\begin{array}{c}\text { Benson et al. } \\
3\end{array}$} \\
\hline 1 & $\begin{array}{l}\text { Parent Rating Scales, Behavior Assessment System for Children, } \\
\text { Third Edition (BASC-3-PRS) }\end{array}$ & & & \\
\hline 2 & $\begin{array}{l}\text { Teacher Rating Scales, Behavior Assessment System for Children, } \\
\text { Third Edition (BASC-3) }\end{array}$ & 94.2 & RS 2 & 1 \\
\hline 3 & Wechsler Intelligence Scale for Children, Fifth Edition (WISC-V) & 92.8 & COG 1 & 2 \\
\hline 4 & CBM oral reading fluency probes & 88.4 & $\mathrm{ACH} 1$ & 5 \\
\hline 5 & Woodcock-Johnson IV Tests of Achievement (WJ IV ACH) & 87.3 & $\mathrm{ACH} 2$ & 12 \\
\hline 6 & $\mathrm{CBM}$ reading comprehension probes & 84.9 & $\mathrm{ACH} 3$ & 6 \\
\hline 7 & Developmental history interview completed with parent or caregiver & 84.1 & IN 1 & 4 \\
\hline 8 & Functional behavior assessment, $\mathrm{ABC}$ recording form & 82.6 & OB 1 & 23 \\
\hline 9 & Woodcock-Johnson IV Tests of Cognitive Ability (WJ IV COG) & 81.2 & COG 2 & 31 \\
\hline 10 & CBM math computation probes & 76.7 & $\mathrm{ACH} 4$ & 13 \\
\hline 11 & Wechsler Individual Achievement Test, Third Edition (WIAT-III) & 76.1 & $\mathrm{ACH} 5$ & 10 \\
\hline 12 & Functional assessment interview completed with teacher & 73.9 & IN 2 & 25 \\
\hline 13 & Observation, interval recording & 72.5 & OB 2 & 14 \\
\hline 14 & Adaptive Behavior Assessment System, Third Edition (ABAS-III) & 71.8 & ADAPT 1 & 18 \\
\hline 14 & $\begin{array}{l}\text { Parent/Caregiver Form, Vineland Adaptive Behavior Scales, Third } \\
\text { Edition (Vineland-3) or prior edition }\end{array}$ & 71.8 & ADAPT 1 & 42 \\
\hline 16 & $\begin{array}{l}\text { Behavior Assessment System for Children (BASC-3) or previous } \\
\text { edition Self-Report of Personality }\end{array}$ & 71.0 & SELF 1 & 11 \\
\hline 17 & CBM early literacy probes & 69.8 & ACH 6 & 9 \\
\hline 17 & CBM math concepts and applications probes & 69.8 & $\mathrm{ACH} 6$ & 17 \\
\hline 19 & $\begin{array}{l}\text { Problem-solving interview (a.k.a. problem identification and problem } \\
\text { analysis interview) completed with teacher }\end{array}$ & 69.6 & IN 3 & 15 \\
\hline 20 & $\begin{array}{l}\text { Kaufman Assessment Battery for Children, Second Edition (KABC- } \\
\text { II) }\end{array}$ & 65.2 & COG 3 & 33 \\
\hline 20 & Event recording & 65.2 & OB 3 & 22 \\
\hline 22 & Kaufman Test of Educational Achievement, Third Edition (KTEA-3) & 64.8 & $\mathrm{ACH} 8$ & 8 \\
\hline 23 & Parent Rating Scales, Conners 3 or prior edition & 63.8 & RS 3 & 19 \\
\hline 23 & Observation, duration recording & 63.8 & OB 4 & 32 \\
\hline 23 & Functional assessment interview completed with parent or caregiver & 63.8 & IN 4 & 34 \\
\hline 26 & $\begin{array}{l}\text { Teacher Form, Vineland Adaptive Behavior Scales, Third Edition } \\
\text { (Vineland-3) or prior edition }\end{array}$ & 63.4 & ADAPT 3 & 40 \\
\hline 27 & Teacher Rating Scales, Conners 3 or prior edition & 62.3 & RS 4 & 16 \\
\hline 27 & $\begin{array}{l}\text { Problem-solving interview (a.k.a. problem identification and problem } \\
\text { analysis interview) completed with parent or caregiver }\end{array}$ & 62.3 & IN 5 & 21 \\
\hline 29 & CBM early numeracy probes & 58.1 & ACH 9 & 20 \\
\hline 30 & $\begin{array}{l}\text { Teacher Form, Behavior Rating Inventory of Executive Function, } \\
\text { Second Edition (BRIEF2) }\end{array}$ & 58.0 & RS 5 & 24 \\
\hline 31 & Interview Form, Vineland Adaptive Behavior Scales, Third Edition & 57.7 & ADAPT 4 & 65 \\
\hline
\end{tabular}


Parent Form, Behavior Rating Inventory of Executive Function,

56.5

RS 6

Second Edition (BRIEF2)

33 CBM spelling probes

55.8

50.7

ACH 10

50

34 Parent Form, Conners Comprehensive Behavior Rating Scales

50.7
50.7

RS 7

54

Behavior Rating Inventory of Executive Function, Second Edition

(5).7

SELF 2

36 (BRIEF2) Self-Report Form

49.3

ACH 11

30 (CTOPP-2)

37 Teacher Form, Conners Comprehensive Behavior Rating Scales

47.8

RS 8

51

Wechsler Preschool and Primary Scale of Intelligence, Fourth Edition

46.4

COG 4

49

(WPPSI-IV)

46.4

OB 5

44

Student Observation System

40 Wechsler Adult Intelligence Scale, Fourth Edition (WAIS-IV)

44.9

44.9

COG 5

56

43.7

OB 6

41

Brief experimental analysis of academic skills (e.g., Can't Do/Won't Do Assessment)

43 Children's Depression Inventory (CDI-2)

44 Behavioral Observation of Students in Schools (BOSS)

$\mathrm{ACH} 12$

44 Beery-Buktenica Development Test of Visual-Motor Integration,

40.6

SELF 3 Sixth Edition (Beery VMI)

40.6

OB 7

Childhood Autism Rating Scale, Second Edition (CARS-2)

40.6

37.7

37.7

36.2

35.2

34.9

31.9

NEURO 1

26

Beck Depression Inventory, Second Edition (BDI-II)

ASD 1

38

Differential Ability Scales, Second Edition (DAS-2)

COG 6

101

Gray Oral Reading Tests, Fifth Edition (GORT-5)

SELF 4

103

CBM written expression probes

COG 729

Child Behavior Checklist, Achenbach System of Empirically Based

ACH 13

52 Functional behavior assessment, conditional probability recording form

52 Beck Anxiety Inventory (BAI)

31.9

ACH 14

27

RS 9

90

Teacher Report Form, Achenbach System of Empirically Based Assessment (ASEBA)

56 KeyMath-3 Diagnostic Achievement

OB 8

Bender Visual-Motor Gestalt Test, Second Edition

NEURO 2 
Draw A Person

Direct Behavior Ratings (DBRs) as a rating scale

Direct Behavior Ratings (DBRs) as an observation method

Wide Range Assessment of Memory and Learning, Second Edition (WRAML-2)

House Tree Person (H-T-P)

Home Version, ADHD Rating Scale -5 for Children and Adolescents

School Version, ADHD Rating Scale -5 for Children and

Adolescents

Kinetic Family Drawing

Conners-Wells Adolescent Self-Report Scale (Conners 3)

Portfolio, performance, or authentic assessment techniques

Comprehensive Test of Nonverbal Intelligence, Second Edition (CTONI-2)

Bayley Scales of Infant and Toddler Development (Bayley-III)

Diagnostic interview completed with child or adolescent (e.g., a structured interview such as the Diagnostic Interview Schedule for Children [DISC-IV])

Woodcock Reading Mastery Tests, Third Edition (WRMT-III)

Parent Form, Comprehensive Executive Function Inventory (CEFI)

Teacher Form, Comprehensive Executive Function Inventory (CEFI)

Reynolds Intellectual Assessment Scale, Second Edition (RIAS-2)

Diagnostic interview completed with parent or caregiver (i.e., a structured interview such as the Diagnostic Interview Schedule for Children [DISC-IV])

Wechsler Intelligence Scale for Children ${ }^{\circledR}$-Fifth Edition, Integrated (WISC-V Integrated)

Cognitive Assessment System, Second Edition (CAS-2)

Battelle Developmental Inventory ${ }^{\mathrm{TM}}$, Second Edition (BDI-2)

Achenbach System of Empirically Based Assessment (ASEBA)

Direct Observation Form

Multidimensional Anxiety Scale for Children, Second Edition

(MASC-2)

Reynolds Child Depression Scale, Second Edition (RCDS-2)

Autism Diagnostic Observation Schedule, Second Edition (ADOS-2)

Bracken Basic Concepts Scale, Third Edition: Receptive (BBCS-3:R)

Delis-Kaplan Executive Function System (DKEFS)

Minnesota Multiphasic Personality Inventory-Adolescent, Restructured Form (MMPI-A RF)

Reynolds Adolescent Depression Scale, Second Edition (RADS-2)

Parent Form, Social Skills Improvement System-Performance

Screening Guide (SSIS-PSG)

Teacher Form, Social Skills Improvement System-Performance

Screening Guide (SSIS-PSG)

Roberts Apperception Test for Children, Second Edition (Roberts-2)

Thematic Apperception Test (TAT)

Kaufman Brief Intelligence Test, Second Edition (KBIT-2)

Millon Adolescent Clinical Inventory (MACI)
SELF 10

SELF 10

ASD 3

PT 5

PT 5 
Self-Report, Social Skills Improvement System-Performance Screening Guide (SSIS-PSG)

102 Gilliam Asperger's Disorder Scale (GADS)

106 Developmental Assessment of Young Children-Second Edition (DAYC-2)

106 Test of Memory and Learning, Second Edition (TOMAL-2)

106 Personality Inventory for Children, Second Edition (PIC-2)

109 Informal Reading Inventory (IRI)

110 Leiter International Performance Scale, Third Edition (Leiter-3)

110 Developmental Indicators for the Assessment of Learning-Fourth Edition (DIAL-4)

110 Continuous performance tests

113 Scales of Independent Behavior-Revised (SIB-R)

114 Parent Informant, Vanderbilt Assessment Scales, Second Edition

114 Teacher Informant, Vanderbilt Assessment Scales, Second Edition

114 BRIGANCE Inventory of Early Development II (IED II)

114 Wisconsin Card Sorting Test

114 Rorschach Inkblot Test

119 Social, Academic, and Emotional Behavior Risk Screeners (SAEBRS)

119 Wechsler Abbreviated Scale of Intelligence-Second Edition (WASIII)

121 Stroop Color and Word Test

122 Parent Rating Scales, Clinical Assessment of Behavior (CAB)

122 Teacher Rating Scales, Clinical Assessment of Behavior (CAB)

122 School Social Behavior Scales (SSBS)

122 Mullen Scales of Early Learning

122 Attention Deficit Hyperactivity Disorder School Observation Code

122

122

122

122

131

132

132

134

134

134

134

134

134

134

134

Dean-Woodcock Sensory-Motor Battery

Motor-Free Visual Perception Test-4 (MVPT-4)

State-Trait Anxiety Inventory for Children (STAIC)

Suicidal Ideation Questionnaire (SIQ)

Autism Spectrum Rating Scales

Reynolds Intellectual Screening Test (RIST)

State-Event Classroom Observation System (SECOS)

Iowa Test of Basic Skills (ITBS)

Devereux Student Strengths Assessment (DESSA)

Gifted Rating Scales

Boehm Test of Basic Concepts, Third Edition (Boehm-3)

Learning Propensity Assessment Device (LPAD) (or variation thereof)

Batería III Woodcock

Classroom Assessment Scoring System (CLASS)

Systematic Screening of Behavior Disorders-Second Edition (SSBD2)

142 Social Responsiveness Scale, 2nd Edition

143 Scholastic Math Inventory

143 Scholastic Reading Inventory
11.6

SELF 15

117

11.6

ASD 4

107

10.1

EARLY 4

70

10.1

NEURO 7

106

10.1

9.9

8.7

8.7

8.7

8.5

7.2

7.2

7.2

7.2

7.2

5.8

5.8

SELF 16

ACH 19

132

110

123

COG 14

102

119

131

ADAPT 5

RS 19

RS 19

66

61

EARLY 6

113

NEURO 9

137

PT 7

130

RS 21

121

COG 15

69

5.8

NEURO 10

124

RS 22

RS 22

RS 24

EARLY 7

OB 11

NEURO 11

NEURO 11

SELF 17

SELF 17

ASD 5

COG 16

OB 12

ACH 20

RS 25

RS 25

EARLY 8

EARLY 8

125

122

129

147

126

127

120

139

116

43

134

138

109

135

73

1.4

1.4

1.4

EARLY 8

OB 13

OB 13

148

149

1.4

1.4

0.8

ASD 6

ACH 22

ACH 22
94

142

143

88

95

68 
143 Impairment Rating Scale

143 Kaufman Adolescent and Adult Intelligence Test (KAIT)

143 Merrill-Palmer, Revised Scales of Development

143 Revised Edition of the School Observation Coding System (REDSOCS)

143 Halstead-Reitan Neuropsychological Test Battery

$\begin{array}{lcl}0.0 & \text { RS } 27 & 146 \\ 0.0 & \text { COG } 17 & 140 \\ 0.0 & \text { EARLY 11 } & 150 \\ 0.0 & \text { OB } 15 & 144\end{array}$

0.0

NEURO 13

Note . $\mathrm{RS}=$ rating scale, $\mathrm{COG}=$ cognitive ability test, $\mathrm{IN}=$ interview, $\mathrm{ACH}=$ academic achievement test, $\mathrm{SELF}=$ self-report scale, $\mathrm{OB}=$ observation, $\mathrm{ADAPT}=$ adaptive behavior scale, $\mathrm{ASD}=$ autism spectrum disorder scale, $\mathrm{NEURO}=$ neuropsychological test, $\mathrm{PT}=$ projective test or technique, EARLY = early childhood/developmental assessment. 


\section{Table 4}

Online or software-based technology for scoring and administered by instrument type.

\begin{tabular}{llllll}
\hline Instrument Type & \multicolumn{2}{l}{ Scored } & & \multicolumn{2}{l}{ Administered } \\
\cline { 2 - 3 } \cline { 5 - 6 } \cline { 5 - 6 } & Percent & Percent $S D$ & & Percent & Percent $S D$ \\
\hline Behavior rating scales & $58.8^{\mathrm{c}}$ & 31.8 & $28.0^{\mathrm{b}}$ & 26.1 \\
Cognitive ability tests & 56.1 & 29.8 & & $20.7^{\mathrm{b}}$ & 28.1 \\
Academic achievement tests & 53.7 & 27.5 & & $19.2^{\mathrm{c}}$ & 21.3 \\
Self-report rating scales & $45.3^{\mathrm{c}}$ & 32.8 & & $27.4^{\mathrm{b}}$ & 30.0 \\
Adaptive behavior scales & $41.9^{\mathrm{c}}$ & 34.1 & & $19.8^{\mathrm{b}}$ & 20.6 \\
Developmental tests & $25.5^{\mathrm{b}}$ & 32.9 & & $12.0^{\mathrm{a}}$ & 21.7 \\
Behavior observations & $24.9^{\mathrm{b}}$ & 27.5 & & $20.9^{\mathrm{b}}$ & 26.6 \\
Neuropsychological tests & $24.3^{\mathrm{a}}$ & 30.8 & & $14.3^{\mathrm{a}}$ & 25.3 \\
Interviews & $21.1^{\mathrm{b}}$ & 33.0 & $21.5^{\mathrm{a}}$ & 30.5 \\
\hline
\end{tabular}

andicates items with greater than $50 \%$ missing data after accounting for dropout. ${ }^{b}$ Indicates between $20-50 \%$ missing data after accounting for dropout. 'Indicates between $10-20 \%$ missing data after accounting for dropout. All other items have $10 \%$ or less missing data after accounting for dropout. 